\title{
25 Research Square \\ Identification of Hub Genes And Potential Molecular Mechanisms In Peripheral Blood Mononuclear Cells of Patients With Parkinson's Disease
}

Zhi-Hui Li

Harbin Medical University

Guang-Tian Wang

Harbin Medical University

Chun-Ling Chi

Harbin Medical University

Yu-Nan Zhou

Harbin Medical University

Dan Liu

Harbin Medical University

Feng-Shuang Wang

Harbin Medical University

Bin Liu ( $D$ liubinhmu@163.com )

Harbin Medical University https://orcid.org/0000-0002-1418-0124

\section{Research Article}

Keywords: Parkinson's disease, Differentially expressed genes, Protein-protein interaction, Peripheral blood mononuclear cells, Bioinformatics analysis

Posted Date: December 22nd, 2021

DOI: https://doi.org/10.21203/rs.3.rs-1154736/v1

License: (a) (i) This work is licensed under a Creative Commons Attribution 4.0 International License. Read Full License 


\section{Abstract}

Parkinson's disease (PD) is the second most common neurodegenerative disease. The pathogenesis of PD remains elusive, however PD appears to be caused by a complex interaction between environmental and genetic factors affecting various biological processes. The purpose of the present study is to identify hub genes and potential molecular mechanisms in peripheral blood mononuclear cells (PBMCs) of PD patients to aid early diagnosis and start treatment promptly. Two gene expression profiles (GSE22491 and GSE100054) were obtained from the Gene Expression Omnibus (GEO) database, in which 20 PBMC samples from PD patients and 17 controls were included, and the genes were analyzed with GEO2R. 1382 and 512 differentially expressed genes (DEGs) were identified in GSE22491 and GSE100054, respectively. Additionally, a total of 80 significant DEGs were found to co-exist in the two microarray datasets via Venn diagram. Gene Ontology (GO) and Kyoto Encyclopedia of Genes and Genomes (KEGG) pathway enrichment analyses were performed, which showed that the DEGs were mainly enriched in platelet degranulation, blood coagulation, nitric oxide mediated signal transduction, positive regulation of GTPase activity and cellular response to lipopolysaccharide. PPI network, microRNA (miRNA) - hub gene network, and transcription factor (TF)- hub gene network were constructed. In summary, the present study provides data of potential diagnostic biomarkers and therapeutic targets for PD. SRC may be a potential target for the treatment of PD. Additionally, three TFs (HNF4A, CDX2 and FUS), three miRNAs (hsa-miR-165p, hsa-miR-103a-3p and hsa-miR-107), may be involved in PD.

\section{Full Text}

This preprint is available for download as a PDF.

\section{Tables}

Table 1 Characteristics of the microarray datasets from GEO database.

\begin{tabular}{|lllllll|}
\hline GEO Accession & PMID & Platform & $n$ & $\begin{array}{l}\text { Number of } \\
\text { PD patients }\end{array}$ & $\begin{array}{l}\text { Number of } \\
\text { healthy controls }\end{array}$ & References \\
\hline GSE22491 & 20096956 & GPL6480 & 18 & 10 & 8 & 1 \\
\hline GSE100054 & 29223072 & GPL23126 & 19 & 10 & 9 & 2 \\
\hline
\end{tabular}

Table $2 \mathrm{GO}$ analysis and KEGG pathway analysis of the DEGs 


\begin{tabular}{|c|c|c|c|}
\hline Term & Description & $\begin{array}{l}\text { Gene } \\
\text { number }\end{array}$ & $P$ value \\
\hline \multicolumn{4}{|l|}{$\begin{array}{l}\text { biological } \\
\text { process }\end{array}$} \\
\hline GO:0002576 & platelet degranulation & 8 & 0.0000001 \\
\hline GO:0007596 & blood coagulation & 8 & 0.0000056 \\
\hline G0:0007263 & nitric oxide mediated signal transduction & 3 & 0.0022734 \\
\hline GO:0043547 & positive regulation of GTPase activity & 8 & 0.0050983 \\
\hline GO:0071222 & cellular response to lipopolysaccharide & 4 & 0.0087910 \\
\hline GO:0030168 & platelet activation & 4 & 0.0092216 \\
\hline GO:0050900 & leukocyte migration & 4 & 0.0108249 \\
\hline G0:0031623 & receptor internalization & 3 & 0.0113315 \\
\hline GO:0051781 & positive regulation of cell division & 3 & 0.0134357 \\
\hline G0:0006631 & fatty acid metabolic process & 3 & 0.0162846 \\
\hline G0:0007166 & cell surface receptor signaling pathway & 5 & 0.0194747 \\
\hline G0:0001933 & negative regulation of protein phosphorylation & 3 & 0.0219959 \\
\hline G0:0032496 & response to lipopolysaccharide & 4 & 0.0236951 \\
\hline GO:0007155 & cell adhesion & 6 & 0.0287152 \\
\hline G0:0060100 & positive regulation of phagocytosis, engulfment & 2 & 0.0296292 \\
\hline G0:0042127 & regulation of cell proliferation & 4 & 0.0322611 \\
\hline G0:0006930 & substrate-dependent cell migration, cell extension & 2 & 0.0332716 \\
\hline GO:0071404 & $\begin{array}{l}\text { cellular response to low-density lipoprotein particle } \\
\text { stimulus }\end{array}$ & 2 & 0.0332716 \\
\hline GO:0050731 & $\begin{array}{l}\text { positive regulation of peptidyl-tyrosine } \\
\text { phosphorylation }\end{array}$ & 3 & 0.0379707 \\
\hline \multicolumn{4}{|l|}{$\begin{array}{l}\text { cellular } \\
\text { component }\end{array}$} \\
\hline G0:0031092 & platelet alpha granule membrane & 4 & 0.000017 \\
\hline G0:0031093 & platelet alpha granule lumen & 5 & 0.000069 \\
\hline G0:0005615 & extracellular space & 16 & 0.000244 \\
\hline G0:0005886 & plasma membrane & 31 & 0.000311 \\
\hline GO:0070062 & extracellular exosome & 22 & 0.002681 \\
\hline
\end{tabular}




\begin{tabular}{|llll|}
\hline GO:0005925 & focal adhesion & 6 & 0.020252 \\
\hline GO:0005884 & actin filament & 3 & 0.027985 \\
\hline GO:0008074 & guanylate cyclase complex, soluble & 2 & 0.035487 \\
\hline GO:0031090 & organelle membrane & 3 & 0.047592 \\
\hline GO:0045121 & membrane raft & 4 & 0.049760 \\
\hline $\begin{array}{l}\text { molecular } \\
\text { function }\end{array}$ & & & \\
\hline GO:0005543 & phospholipid binding & 4 & 0.004636 \\
\hline GO:0020037 & heme binding & 4 & 0.016497 \\
\hline GO:0004383 & guanylate cyclase activity & 2 & 0.034650 \\
\hline KEGG pathway & & & \\
\hline hsa04611 & platelet activation & 5 & 0.003259 \\
\hline hsa00230 & purine metabolism & 5 & 0.009495 \\
\hline
\end{tabular}

Table 3 KEGG pathway analysis of the top 3 modules from the protein-protein interaction network.

\begin{tabular}{|clllll|}
\hline Category & Term & Description & Gene number & $P$ value \\
\hline Module 1 & hsa04062 & Chemokine signaling pathway & 10 & $2.77 \mathrm{E}-11$ \\
& hsa04727 & GABAergic synapse & 7 & 7 & $1.36 \mathrm{E}-08$ \\
& hsa05032 & Morphine addiction & 7 & $2.06 \mathrm{E}-08$ \\
& hsa04713 & Circadian entrainment & 7 & $2.68 \mathrm{E}-08$ \\
\hline hsa04723 & Retrograde endocannabinoid signaling & 4 & $3.88 \mathrm{E}-08$ \\
\hline & hsa04260 & Cardiac muscle contraction & 4 & $1.23 \mathrm{E}-05$ \\
\hline & hsa05410 & Hypertrophic cardiomyopathy (HCM) & 3 & $7.67 \mathrm{E}-05$ \\
\hline Module 3 & hsa04144 & Endocytosis & 3 & 0.001242 \\
\hline & hsa04510 & Focal adhesion & 5 & 0.001439 \\
\hline & hsa05100 & Bacterial invasion of epithelial cells & 3 & $1.61 \mathrm{E}-04$ \\
\hline
\end{tabular}

Table 4 Functional roles of 10 hub genes 


\begin{tabular}{|c|c|c|}
\hline $\begin{array}{l}\text { Gene } \\
\text { symbol }\end{array}$ & Full name & Function \\
\hline VWF & von Willebrand factor & $\begin{array}{l}\text { Pathways: PI3K-Akt signaling pathway and Focal adhesion; GO: } \\
\text { immunoglobulin binding and protease binding }\end{array}$ \\
\hline SRC & SRC proto-oncogene & $\begin{array}{l}\text { Pathways: GABAergic synapse and Chemokine signaling } \\
\text { pathway; GO: kinase activity and protein binding }\end{array}$ \\
\hline ACTN2 & actinin alpha 2 & $\begin{array}{l}\text { Pathways: Arrhythmogenic right ventricular cardiomyopathy; } \\
\text { GO: identical protein binding and ion channel binding }\end{array}$ \\
\hline $\mathrm{F} 2$ & coagulation factor II & $\begin{array}{l}\text { Pathways: Platelet activation and Phospholipase } \mathrm{D} \text { signaling } \\
\text { pathway; GO: heparin binding and signaling receptor binding }\end{array}$ \\
\hline KDR & $\begin{array}{l}\text { kinase insert domain } \\
\text { receptor }\end{array}$ & $\begin{array}{l}\text { Pathways: MAPK signaling pathway and PI3K-Akt signaling } \\
\text { pathway; GO: protein tyrosine kinase activity and vascular } \\
\text { endothelial growth factor binding }\end{array}$ \\
\hline PPBP & $\begin{array}{l}\text { pro-platelet basic } \\
\text { protein }\end{array}$ & $\begin{array}{l}\text { Pathways: Cytokine-cytokine receptor interaction and Chemokine } \\
\text { signaling pathway; GO: CXCR chemokine receptor binding and } \\
\text { chemokine activity }\end{array}$ \\
\hline PRKACA & $\begin{array}{l}\text { protein kinase cAMP- } \\
\text { activated catalytic } \\
\text { subunit alpha }\end{array}$ & $\begin{array}{l}\text { Pathways: Dopaminergic synapse and Wnt signaling pathway; } \\
\text { GO: cAMP-dependent protein kinase activity and ubiquitin } \\
\text { protein ligase binding }\end{array}$ \\
\hline SELP & selectin $P$ & $\begin{array}{l}\text { Pathways: Cell adhesion molecules; GO: calcium ion binding and } \\
\text { protein binding }\end{array}$ \\
\hline PF4 & platelet factor 4 & $\begin{array}{l}\text { Pathways: Cytokine-cytokine receptor interaction and Chemokine } \\
\text { signaling pathway; GO: CXCR chemokine receptor binding and } \\
\text { chemokine activity }\end{array}$ \\
\hline CCL5 & $\begin{array}{l}\mathrm{C}-\mathrm{C} \text { motif chemokine } \\
\text { ligand } 5\end{array}$ & $\begin{array}{l}\text { Pathways: Chemokine signaling pathway and TNF signaling } \\
\text { pathway; GO: CCR chemokine receptor binding and chemokine } \\
\text { activity }\end{array}$ \\
\hline
\end{tabular}

\section{Figures}


a

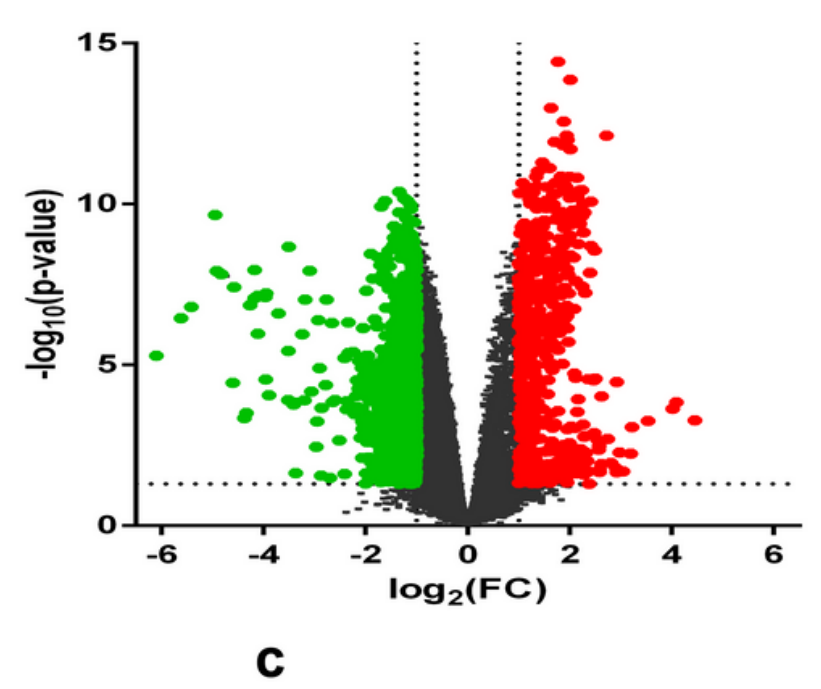

b

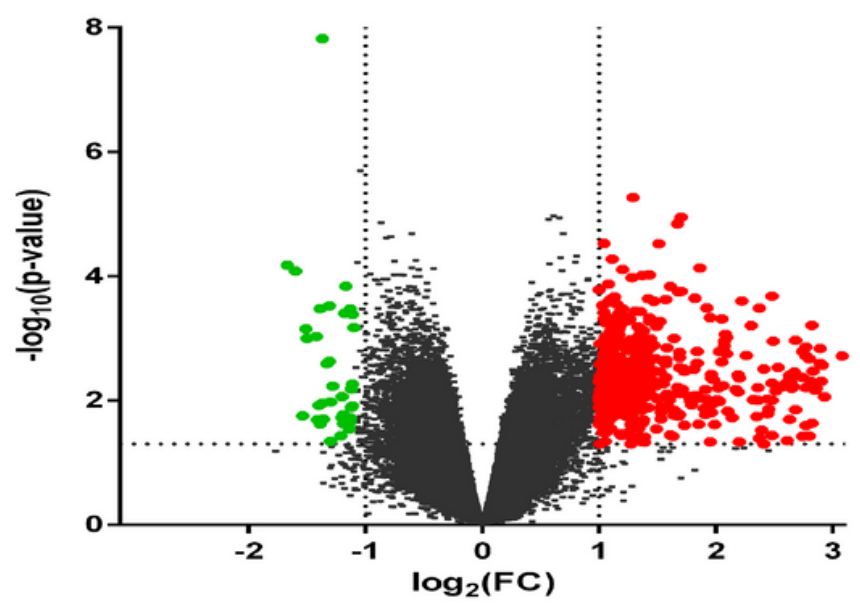

GSE100054

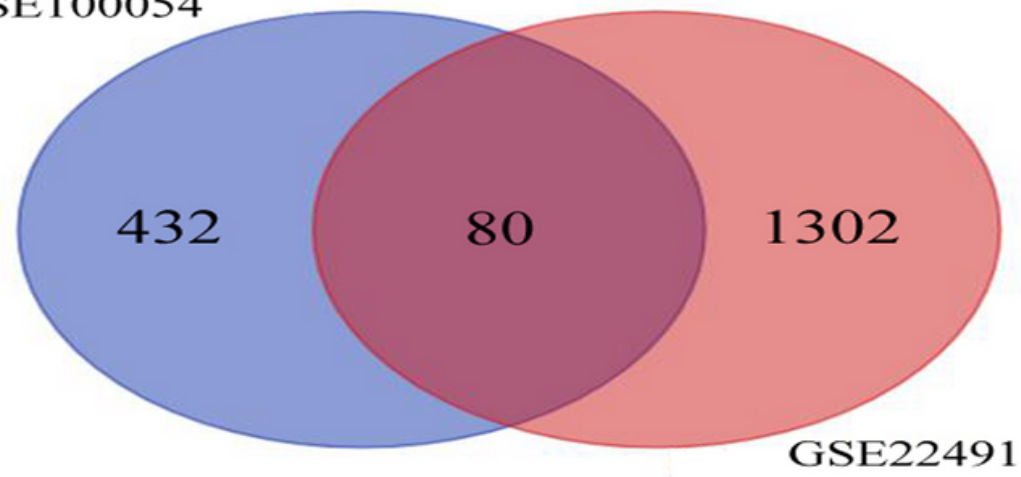

Figure 1

Identification of differentially expressed genes. a Volcano plot of GSE22491 data, b Volcano plot of GSE100054 data. Red points, significantly upregulated genes. Green points, significantly downregulated genes. Black points, genes with no significant difference, $c$ Venn diagram of DEG selection in microarray datasets 
a

Biology Process

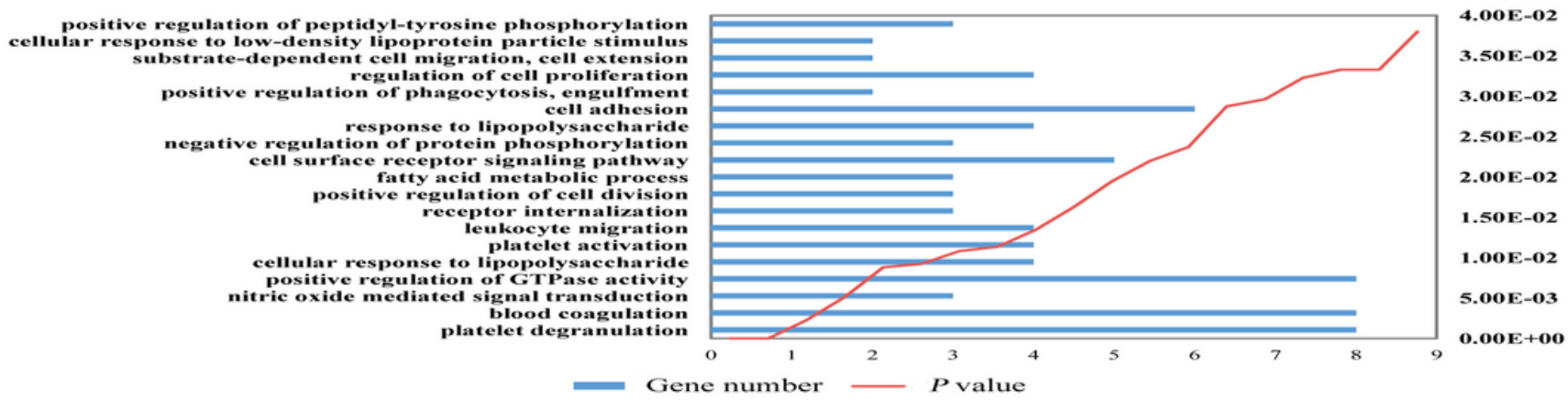

b

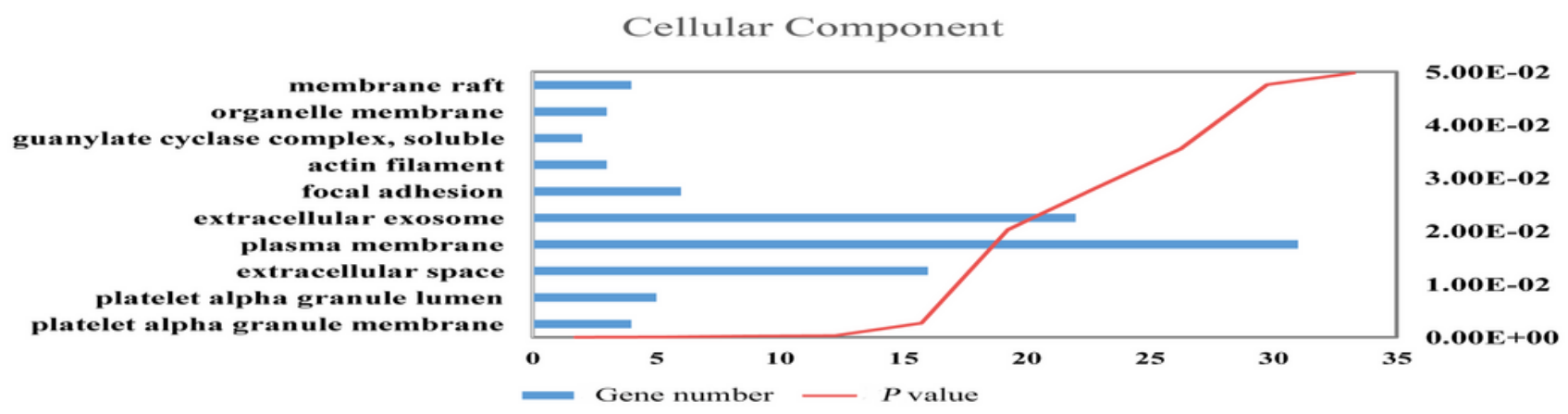

C

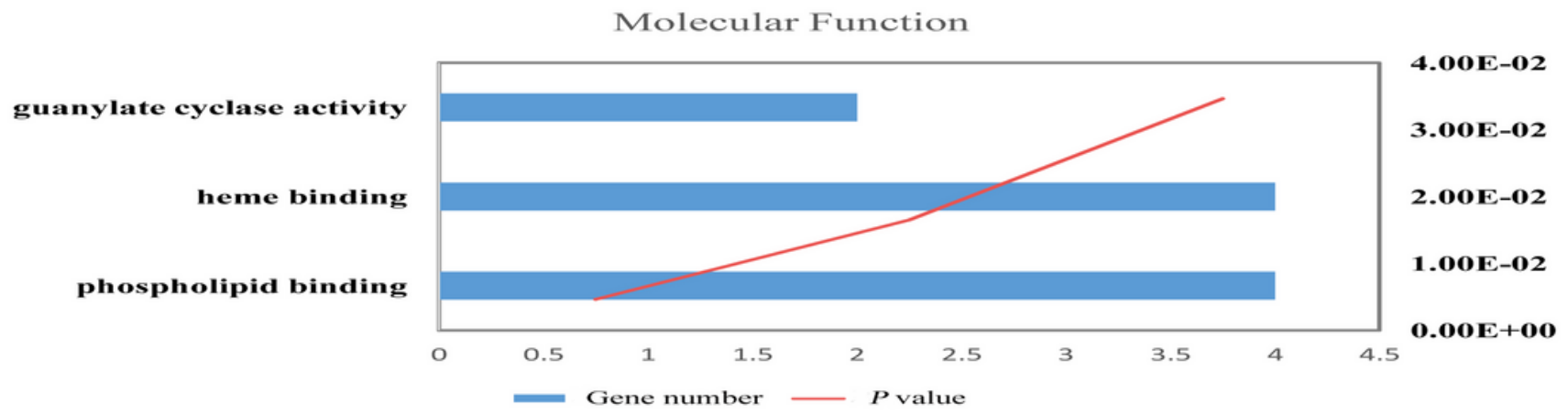

Figure 2

Enriched Gene Ontology terms of differentially expressed genes obtained from the Database for Annotation. a biological process (BP), b cellular component (CC), c molecular function (MF) 


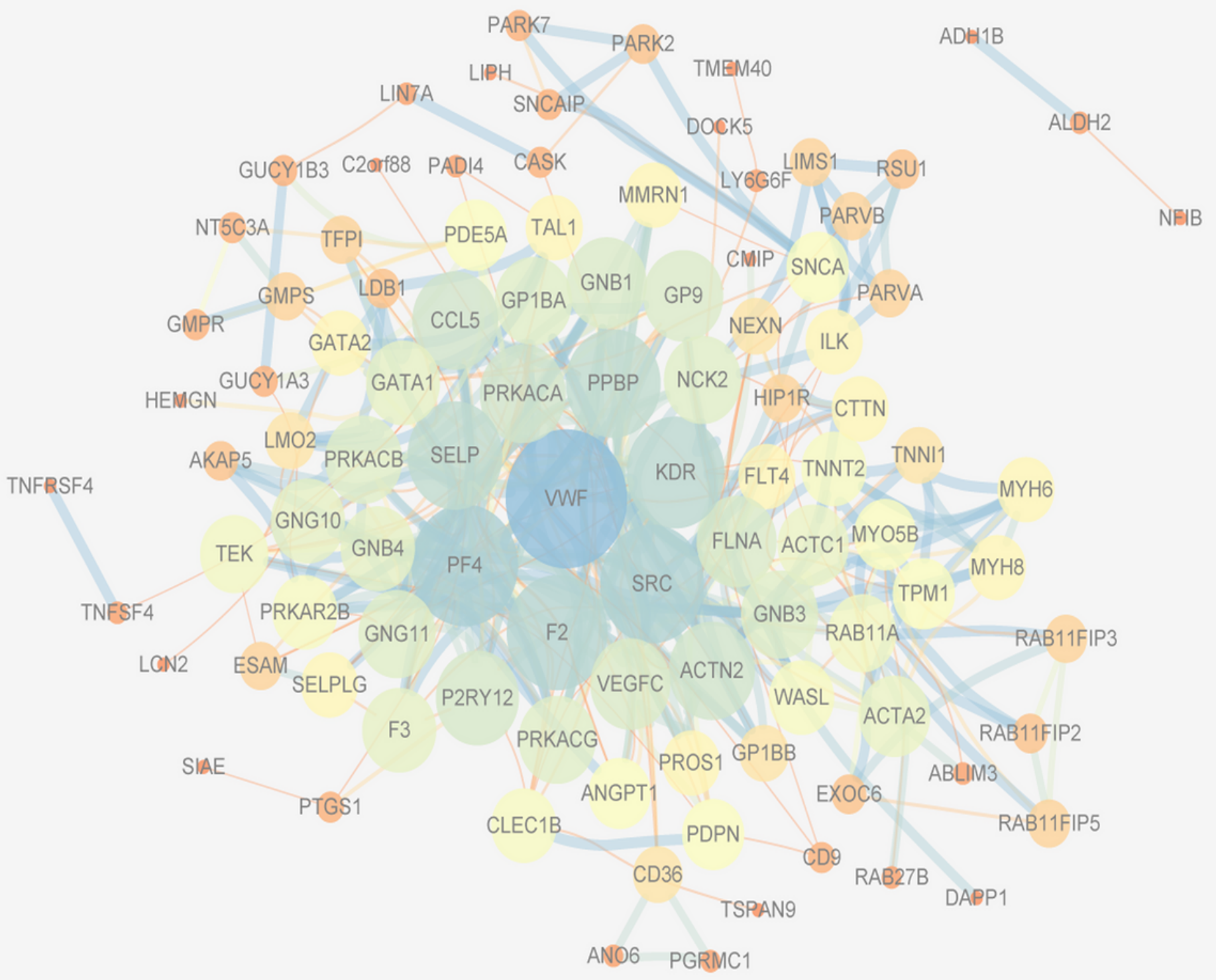

\section{Figure 3}

Protein- protein interaction network of DEGs 


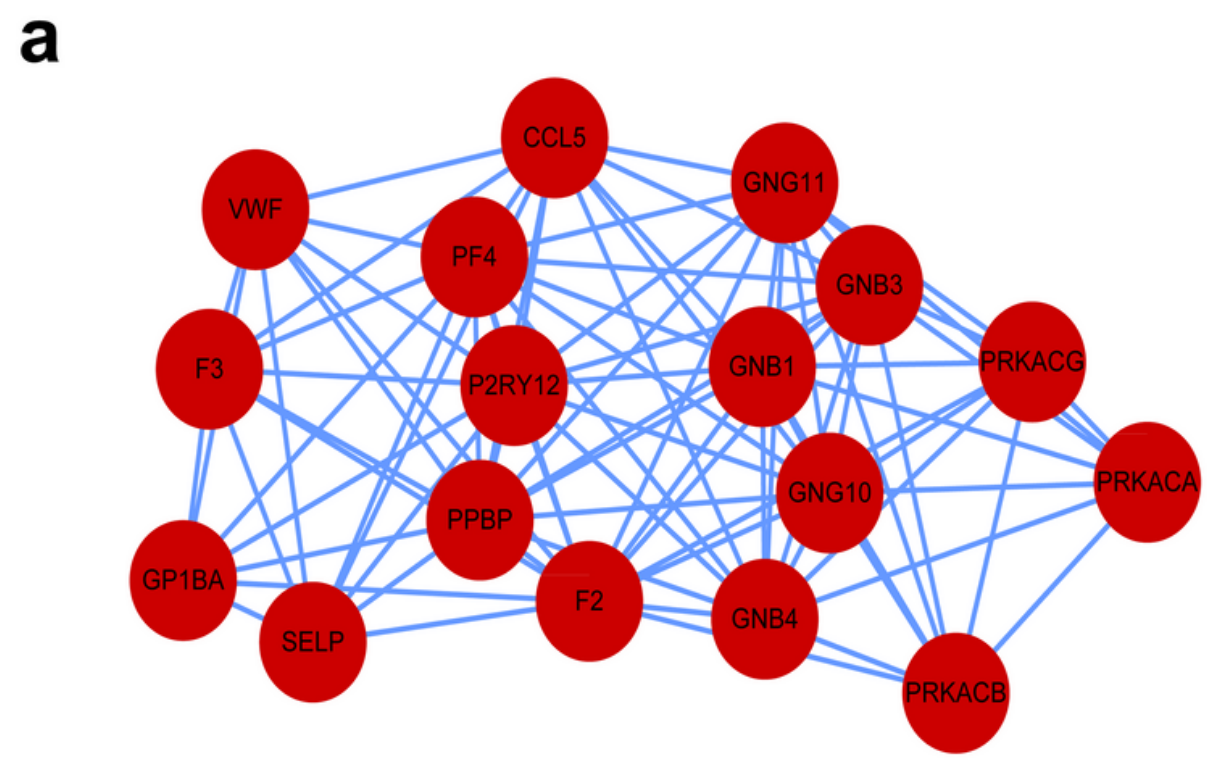

b

C
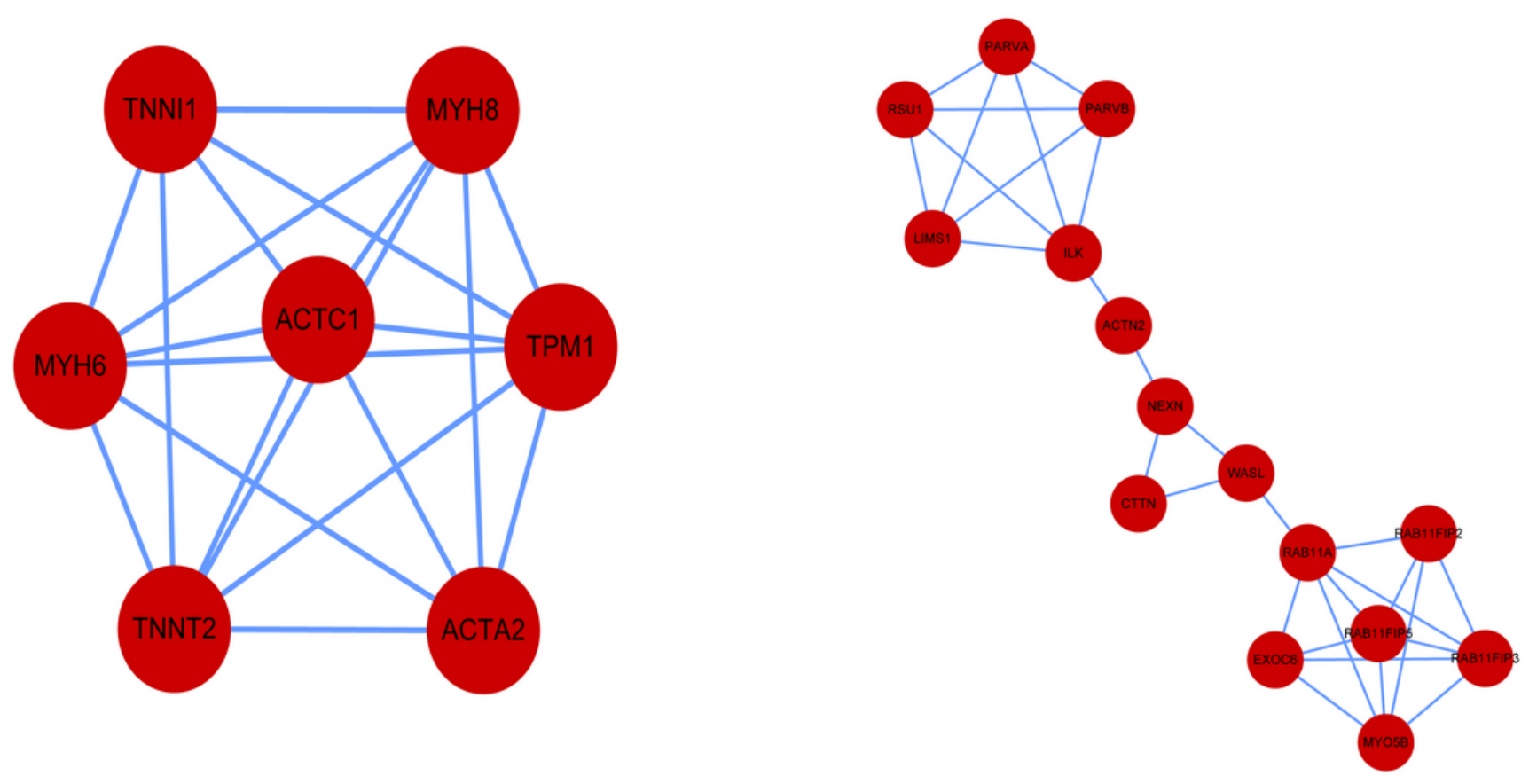

Figure 4

Top 3 modules from the PPI network. a module 1: Score $=11.125, \mathrm{~b}$ module 2: Score $=6.667, \mathrm{c}$ module 3 : Score $=4.286$ 
a

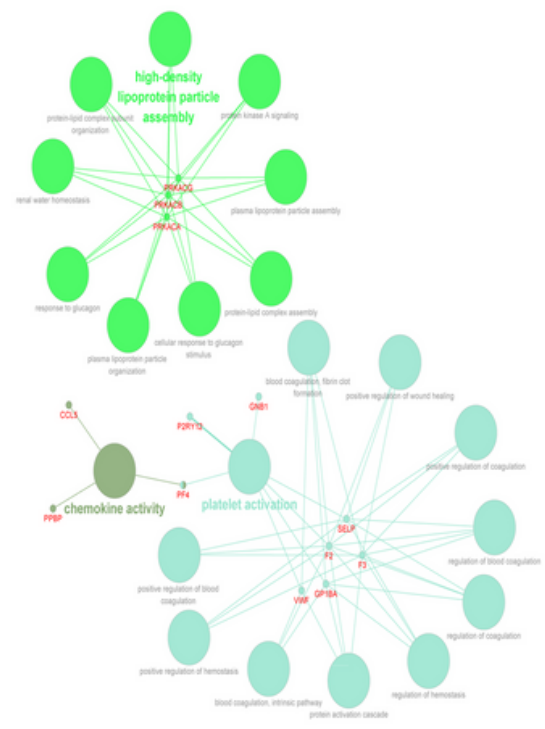

b

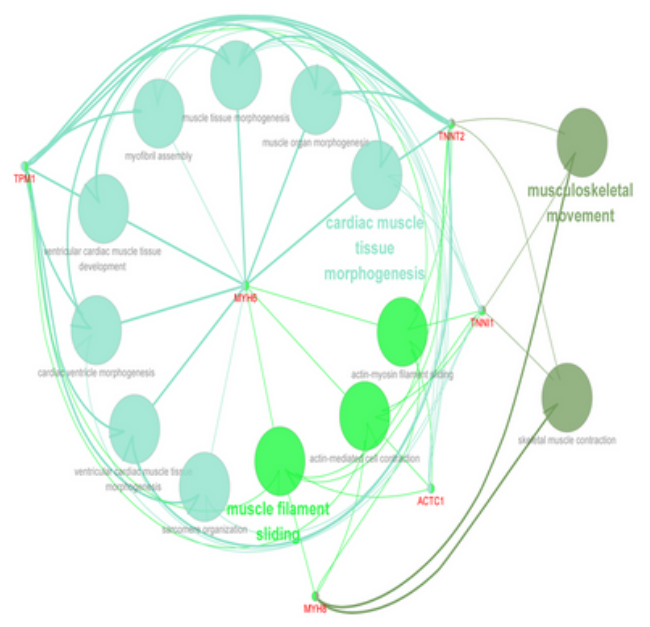

C

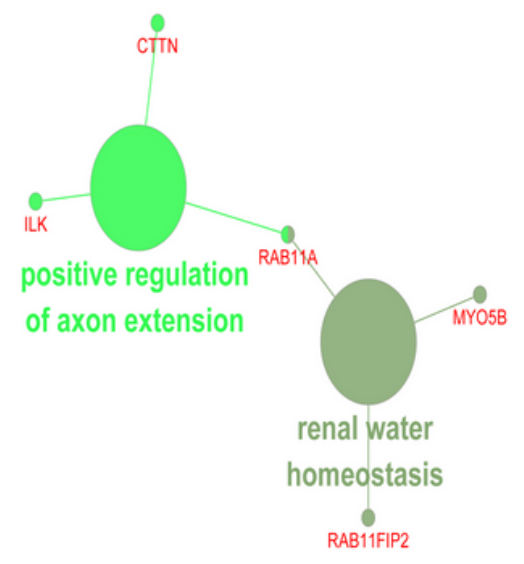

Figure 5

The biologic process analysis of the top 3 modules. a module 1, b module 2, c module 3 . Different colors of nodes refer to the functional annotation of ontologies

a

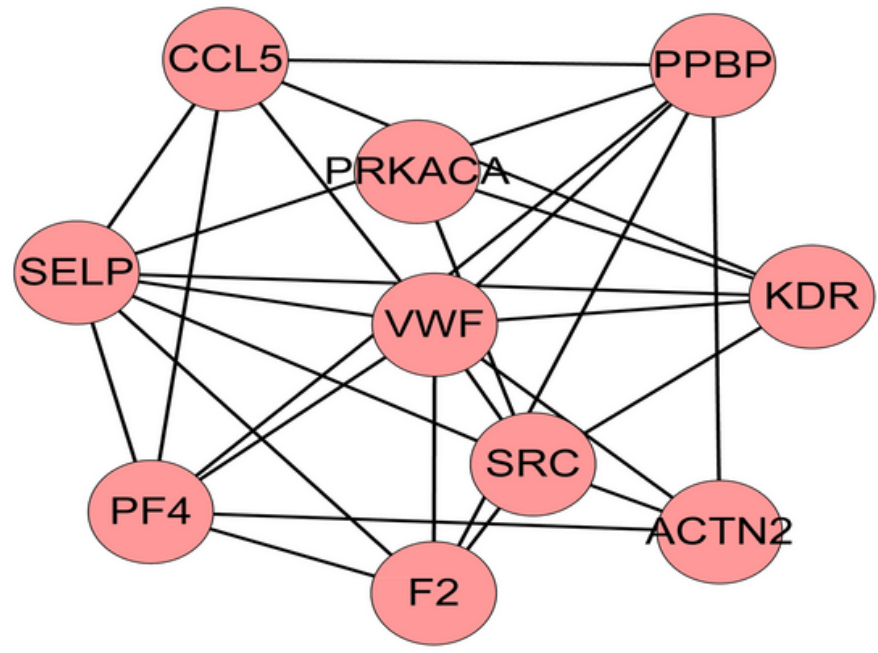

b

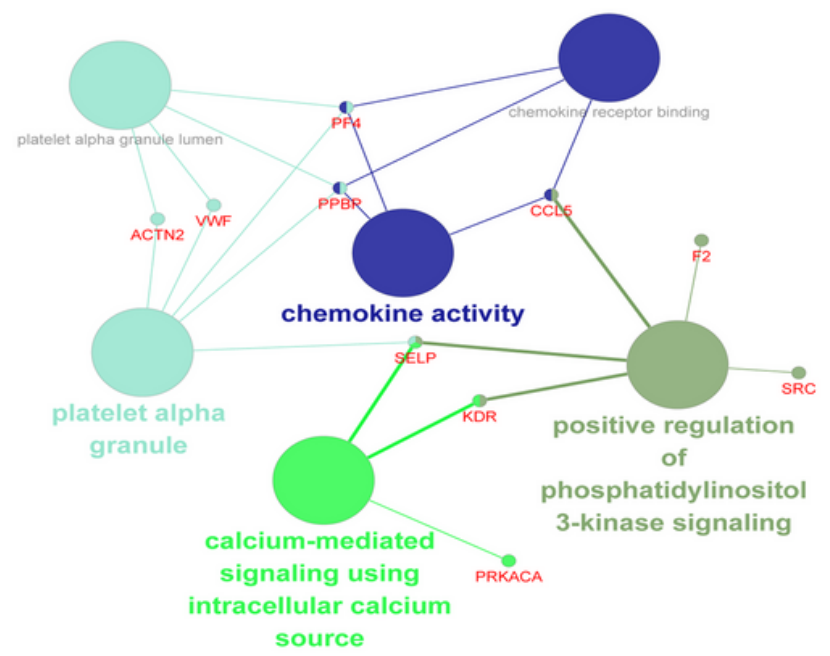

Figure 6

Interaction network and analysis of the hub genes. a PPI network of top 10 hub genes, b The biologic process analysis of hub genes. Different colors of nodes refer to the functional annotation of ontologies. $\mathrm{P}<0.05$ was considered statistically significant 


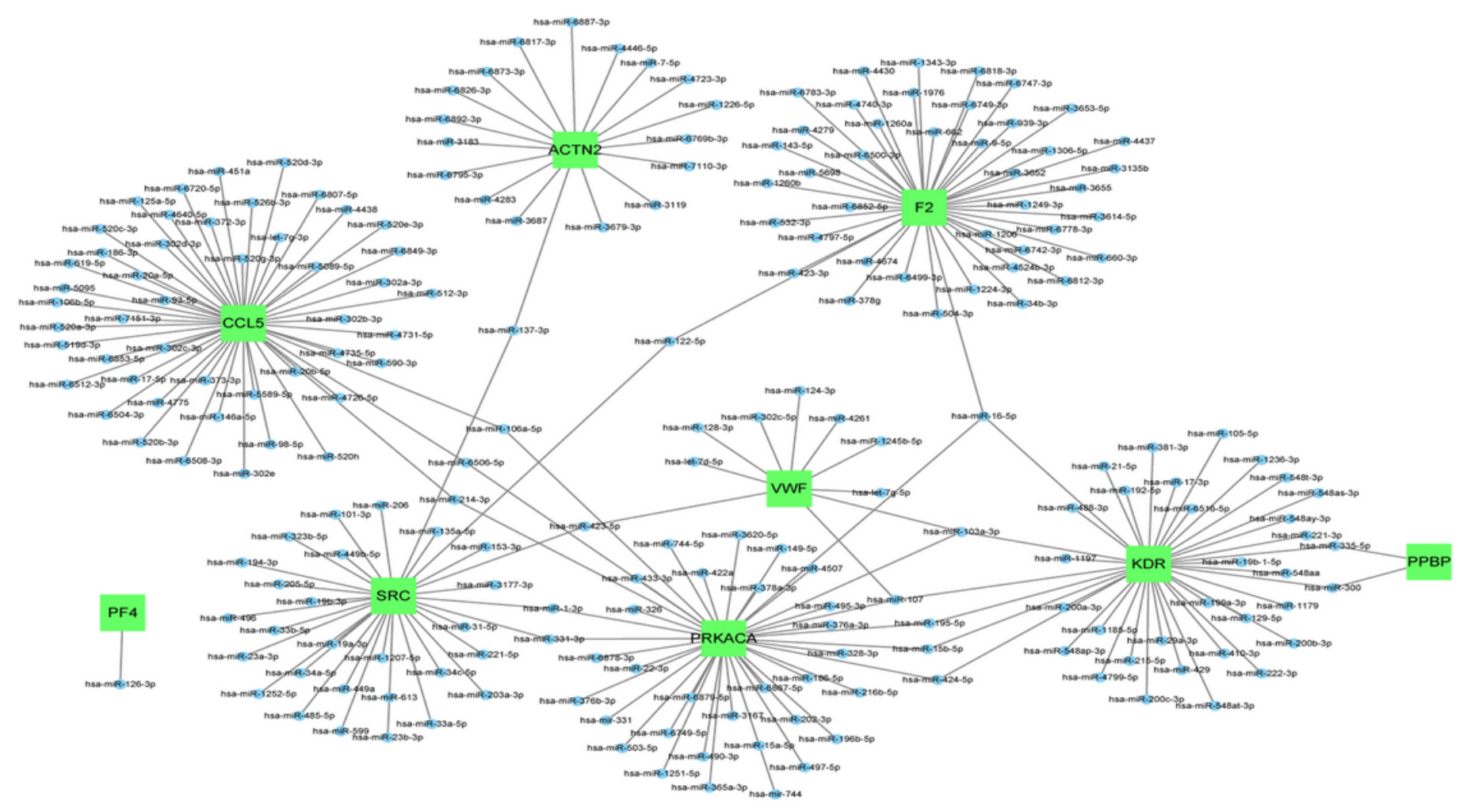

Figure 7

MiRNA-target networks of hub genes. Blue circles represent miRNAs, and green rectangles represent hub genes 


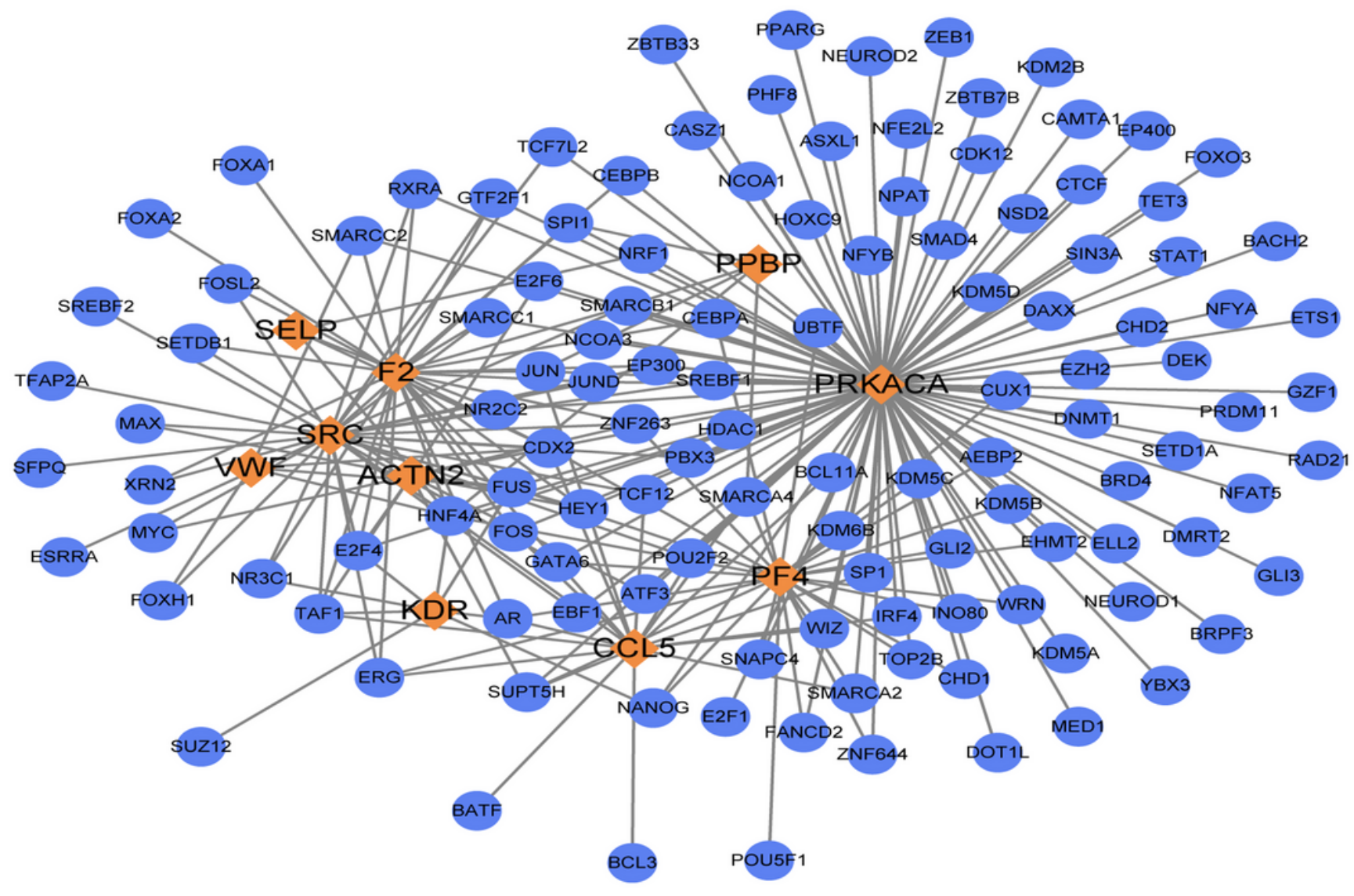

Figure 8

TF-hub gene network. Blue circles represent TFs, and orange diamonds represent hub genes

\section{Supplementary Files}

This is a list of supplementary files associated with this preprint. Click to download.

- Supplementarytable1.doc 